\title{
FOREWORD: DEGLACIATION IN EUROPE. NEW INSIGHTS AND QUESTIONS
}

This issue of Cuadernos de Investigación Geográfica is devoted to a review of various aspects of post-Last Glacial Maximum (LGM) deglaciation throughout Europe. It includes 8 papers considering key areas central to interpreting glacial fluctuations and the definitive retreat of glaciers in Europe, including in Sierra Nevada, southern Spain (A. Gómez-Ortiz, M. Oliva, D. Palacios, F. Salvador-Franch, L. Vázquez-Selem, M. Salvà-Catarineu, N. de Andrés); the Cantabrian Range, northern Spain (E. Serrano, M. Gómez-Lende, R. Pellitero, J.J. González-Trueba); the northern and southern faces of the Pyrenees (M. Delmas); the Apennines (F. Giraudi); the Alps (S. Ivy-Ochs); the Tatra Mountains (M. Makos); northern continental Europe (L. Marks); and Iceland (H.G. Péturson, H. Norðdahl, Ó. Ingólfsson). These areas have in recent times been the subject of intensive study involving complex approaches that include geomorphological mapping and dating, and multiproxy analyses of lake sediments; thus, the interpretations in the accompanying papers are supported by detailed field and laboratory information.

Geomorphology has sometimes erroneously been considered to be an "old science", unable to provide sound and consistent answers to many of the questions raised by the environmental sciences. It is true that geomorphological studies were not able to provide detailed information on many paleoenvironmental problems, including shortterm climatic changes and related issues. Geomorphologists typically considered long-term climatic and landscape topics, although their contributions were significant considering the dating techniques available. Nevertheless, the contributions of paleoenvironmentalists (paleolimnologists, palynologists) have in recent years received more attention because of the scale of their approach, the feasibility of their results and the ease of establishing sequences of events based on the characteristics of sediment, including the occurrence of intense rainstorms, floods, erosion events, and sudden glacial melt events. Meanwhile, geomorphologists studied till fabric, created excellent maps showing the position of moraines, and interpreted the number of glaciations. However, their conclusions were sometimes considered of secondary importance, given the lack of temporal precision and the absence (in many cases) of correlations with data derived from the most advanced approaches.

In recent years the availability of new dates (notably though the application of cosmogenic dating methods to glacial landforms and deposits, and improvements in knowledge of glacial sedimentology) has enabled advances. This has facilitated the interpretation of geomorphological information in a paleoenvironmental context, and has contributed to understanding of the relationships of major glacial events to periglacial processes and fluvial sedimentation downstream of glacier fronts. Techniques 
including ${ }^{14} \mathrm{C}$, optically stimulated luminescence, and cosmogenic exposure dating have facilitated reconstruction of the extent of glacial tongues and ice-sheets at various key stages. In parallel there has been the development and consolidation of multidisciplinary geomorphological research groups including geologists and paleoecologists having complementary views on environmental changes during the Quaternary. Improvements in the available information on atmospheric circulation during the last thousands years have also contributed to interpretation of spatial and temporal variability in the response of glaciers. This explains the occurrence of some asynchronicities at continental and regional scales, which would have been impossible to detect without the help of paleoclimatologists. Palynology has also been a fundamental tool enabling contextualization of glacial and paraglacial erosion and sedimentation, and clarifying the main advances and retreats of the ice sheets and valley glaciers. Today, glacial geomorphology is again an integrative science, based on the excellent work of pioneers during the 19th and 20th centuries, but also incorporating information concerning glacial deposits and landforms to produce models and improve our knowledge of events that have been fundamental to history of the Earth.

Over many decades, geomorphologists distinguished various stages in glacial evolution. Analysis of frontal and lateral moraines enabled identification of a series of glacial advances during the Upper Pleistocene. Many studies, based on sound geomorphological mapping and fieldwork have revealed the position of glacier fronts during the maximum ice extent, and distinguished minor advances that may have been related to cold periods. The results presented in this issue highlight the extent to which paleoenvironmental sciences (particularly Geomorphology) have advanced through the use of increasingly sophisticated dating techniques and have correlated the results obtained from various other scientific disciplines. Deglaciation is a key event in Europe, knowledge of which can: (i) explain how glaciers evolved; (ii) enable correlations of glacial evolution with the establishment of distinct plant communities following the LGM; (iii) enable detection of the response of ice sheets and (particularly) mountain valley glaciers to climate changes; (iv) facilitate interpretation of spatial variability in relation to changes in atmospheric circulation at a continental scale; and (v) aid in assessment of the consequences of glacial advances and retreats on the location of shorelines. Most of these are very important paleoenvironmental issues, and are fundamental to the Earth's future in the mid- and long-term. Some of these issues are the subject of the presented papers, which facilitates analysis of the main events in the evolution of glaciers, and when they occurred, and enable correlation to be made with related paleoenvironmental events including cold and warm periods, dry and wet spells, and the expansion and contraction of forests in Europe. Such analyses will facilitate identification of abrupt changes that could also occur in the future, potentially affecting the survival of humans on Earth.

Geomorphology has contributed to detection of an asynchronicity between the maximum ice extent in most Mediterranean mountains and the LGM in central and northern Europe. Nevertheless, deglaciation events coincide remarkably among the various areas of Europe, including: (i) a rapid and intense glacier retreat between 19 and17 kyr BP, following the LGM; (ii) an expansion of glaciers during the Oldest Dryas (GS-2) (between 17 and 15 kyr BP); (iii) rapid glacier melting during the Bølling-Allerød 
interstadial (14.5-13 kyr BP), which resulted in the almost complete disappearance of glaciers from many European mountains; and (iv) a new, rapid, dry and intense cooling during the Younger Dryas (12.7-11.7 kyr BP), which caused the development of many cirque glaciers delimited by large frontal moraines. The maps that accompany the various papers in this issue show the positions of glaciers in some European mountains during the various stadials.

Some uncertainties that remain and constitute scientific challenges for the immediate future include the following: (i) The absence of a glacial response during the Oldest Dryas in some mountains adjacent to the Atlantic Ocean. Was the cause climatic reasons or a consequence of a lack of adequate glacial deposits? (ii) The absence of geomorphological signals during the Older Dryas. Was this very short cold period in the middle of the BøllingAllerød interstadial unable to produce a clear glacial re-advance with its corresponding moraines? (iii) The presence of a number of moraines corresponding to deglaciation stadials. Were they the consequence of rapid, very short climatic changes, or the result of a variety of topographical conditions? (iv) The occurrence of a generalized stage of rock glacier development at the end of the Oldest Dryas. Was this simply the result of climate deterioration or the effect of bedrock relaxation in the cirque headwalls? (v) The variable length of mountain glaciers during the Younger Dryas. Was this a consequence of climate variability throughout Europe? And (vi) Were the Oldest Dryas rock glaciers reactivated by the Younger Dryas cooling?

These and other questions are in the notebooks of many geomorphologists. To address them will require more fieldwork and detailed geomorphological mapping, as well as determining new dates from bedrock thresholds, and glacial, periglacial and glacio-lacustrine deposits. Collaboration among paleolimnologists, sedimentologists, paleoecologists and palynologists is more necessary than ever. The exchange of information, exemplified by the publications in this issue, is an efficient strategy for solving global problems dependent on knowledge of how deglaciation occurred in Europe.

D. Palacios

Department of Geography, Complutense University of Madrid, 28040 Madrid, Spain.

J.M. García-Ruiz

Instituto Pirenaico de Ecología, CSIC, 50080 Zaragoza, Spain. 